\title{
Healthcare-associated infection in the Grey's Hospital paediatric intensive care unit: does an Infection Control Programme work?
}

\author{
Anne L Armour ${ }^{a, b *}$, Mark E Patrick ${ }^{a, b}$ (D) Zelda Reddy ${ }^{b, c}$, Wilbert Sibanda ${ }^{d}$, Logandran Naidoo ${ }^{b}$ and Kevin B Spicer ${ }^{a}+\mathbb{I D}$ \\ ${ }^{a}$ Department of Paediatrics and Child Health, Nelson R Mandela School of Medicine, University of KwaZulu-Natal, Durban, South Africa \\ ${ }^{b}$ Grey's Hospital, Pietermaritzburg, South Africa \\ 'Infection Prevention and Control Department, Greys Hospital, Pietermaritzburg, South Africa \\ ${ }^{d}$ Statistics Unit, School of Nursing and Public Health, University of KwaZulu-Natal, Durban, South Africa \\ *Corresponding author, email: anniealing@gmail.com

Background: Healthcare-associated infections are an important cause of morbidity and mortality globally. Grey's Hospital introduced an Infection Control Programme in August 2016, which included Best Care Always bundles for reducing the occurrence of central line-associated bloodstream infections, catheter-associated urinary tract infections and ventilatorassociated pneumonia.

Methods: An observational before-after quasi-experiment was conducted retrospectively reviewing healthcare-associated infection rates in the Grey's Hospital paediatric intensive care unit a year prior to (August 2015 to July 2016) and after (September 2016 to August 2017) implementation of an Infection Control Programme.

Results: There was an absolute decrease in healthcare-associated infection from 102 to 81 and a statistically significant decrease in bloodstream infections per 1000 central venous catheter days from 36/1 000-15/1 000 after intervention (RR $0.42,95 \% \mathrm{Cl}$ $0.23-0.79, p=0.004)$. The rate of healthcare-associated infection decreased from $23 / 100$ admissions prior to the intervention to $20 / 100$ admissions after the intervention ( $R R 0.87,95 \% \mathrm{Cl} 0.51-1.48, p=0.61$ ) and from $40 / 1000$ patient days to $32 / 1000$ patient days (RR $0.80,95 \% \mathrm{Cl} 0.51-1.26, p=0.34$ ). Reductions in healthcare-associated infection were also seen in bloodstream infections and urinary tract infections.

Conclusion: The observed downward trend in overall healthcare-associated infections, bloodstream infections and urinary tract infections did not reach statistical significance except for bloodstream infections per 1000 central venous catheter days. Further research or audit is needed to ascertain reasons for this less than expected decrease in healthcare-associated infections. In the meantime, meticulous adherence to bundles should be encouraged.

Keywords: Best Care Always bundle, Grey's Hospital, healthcare-associated infection, Hospital-acquired infection, infection control campaign, nosocomial infection, PICU

\section{Background}

Healthcare-associated infections (HAls) are an important cause of morbidity and mortality globally, especially among critically ill patients admitted to intensive care units (ICUs). ${ }^{1}$ HAls, often due to multidrug resistant organisms, occur in approximately 1 in 10 admissions, leading to increased costs, increased length of stay and increased mortality. ${ }^{2}$ It is estimated that healthcare-associated bloodstream infections (BSIs) may be responsible for 25000 deaths in African children annually. ${ }^{3}$

The burden of HAls is significantly higher in low- and middleincome countries compared with upper-income countries. ${ }^{4}$ $\mathrm{HAI}$ rates in ICUs in low- and middle-income countries are at least double and even sometimes triple the rates of those in the USA. ${ }^{5}$ Due to lack of adequate surveillance programmes in South Africa, there are limited data on local HAI rates. ${ }^{6}$ In a meta-analysis of studies from 1995 to 2008 looking specifically at HAls in low- and middle-income countries, only 13 African studies were included and none was from South Africa. These studies also showed $\mathrm{HAl}$ rates between double and triple those reported in the USA and the UK, highlighting the problem in low- and middle-income countries. This difference was most striking in the ICU setting. ${ }^{7}$
The International Nosocomial Infection Control Consortium, a multinational research network focused on measurement and reduction of HAls, found that rates of device-associated infections were significantly higher in ICUs in low- and middleincome countries than in ICUs in the USA despite similar rates of device utilization. ${ }^{8}$ This comparison was made with data from the report of the Centers for Disease Control and Prevention National Healthcare Safety Network, which reports data from facilities in and around the USA. More recent South African surveillance data have become available and are in keeping with the above-mentioned concern, with rates more than double those in upper-income countries. ${ }^{9}$

Over the last two decades, research in a variety of settings worldwide has focused on interventions targeting the reduction of HAls. The Institute for Healthcare Improvement introduced the bundle concept in 2001. A bundle is a set of evidence-based interventions that when implemented together result in improved patient outcomes. There are bundles targeting central line associated bloodstream infections (CLABSIs), catheter associated urinary tract infections (CAUTIs), ventilator associated pneumonia (VAP), surgical site infections (SSIs) and antibiotic stewardship. This concept was introduced in South 
Africa in 2009 with the Best Care Always (BCA) campaign. ${ }^{10}$ Many studies have shown a significant reduction in infection rates where compliance is achieved. ${ }^{11}$

HAI rates in the Grey's Hospital paediatric intensive care unit (PICU) in 2013 and 2014 were 20.4 and 15.3 per 100 admissions and 27.5 and 33 per 1000 patient days respectively. ${ }^{12}$ This is much higher than the 6.1 per 100 admissions and 14.1 per 1 000 patient days reported for similar units in upper-income countries in a multicentre study in 61 PICUs in the USA. ${ }^{13} \mathrm{~A}$ meta-analysis of studies looking at HAI rates in low- and middle-income countries reported a pooled prevalence of 15.5 per 100 admissions, which was closer to the Grey's Hospital rates. $^{7}$

In response to the high HAI rates in the ICUs at Grey's Hospital, the Infection Prevention and Control Committee implemented an Infection Control Programme initiated by the HospitalAcquired Infections in the ICU Team in August 2016. This programme included the BCA bundles for CLABSI, CAUTI and VAP in addition to other initiatives such as the 'Hands Off' campaign for promoting hand hygiene.

With substantial evidence that bundles decrease HAls, a decrease in HAl rates would be expected when implemented in new sites. The aim of the study was to ascertain if there was a decrease in HAI rates in the Grey's Hospital PICU following the implementation of the Infection Control Programme.

\section{Methods}

The study was conducted in the PICU at Grey's Hospital from August 2015 to August 2017. The PICU at Grey's Hospital is an eight-bed intensive care and high care unit that serves the western part of KwaZulu-Natal, which has a population of approximately 1.2 million children. ${ }^{14}$ There is a high turnover of both medical and surgical cases referred from both regional and district hospitals. The children range in age from 2 weeks to 12 years and come from rural, peri-urban and urban areas. The PICU medical staff consists of nurses, medical officers, registrars and paediatricians. The nursing staff and paediatricians are permanent, but the medical officers, registrars and after-hours paediatricians all work on a rotational basis.

The study was an observational before-after quasi-experiment through retrospective review of HAI rates in the PICU a year prior to (August 2015 to July 2016) and a year after (September 2016 to August 2017) implementation of an Infection Control Programme including the BCA bundles for CLABSI, CAUTI and VAP.

\section{Data sources}

Patient throughput data were sourced from the admissions and separations register as well as from the daily catheter records kept in the PICU. The HAI data were obtained from the Infection Prevention and Control Committee register. This register is compiled by the Infection Prevention and Control Committee using both clinical data from the PICU and microbial culture results obtained from the onsite National Health Laboratory Service (NHLS). Positive cultures are collated and tallied weekly and then sent to the committee for further review. The team reviews microbiological results along with each patient's clinical status to determine whether the infection is currently active and, based on timing of the positive culture in relation to admission, whether it is community acquired or healthcare associated. HAls are defined as those not present or incubating at the time of admission but found in samples taken more than 48 hours after hospital admission. Specimens sent for culture include blood, urine, respiratory aspirates, fluid (pleural, pericardial, peritoneal and cerebrospinal), tissue and superficial swabs. These specimens are usually obtained and sent to the laboratory based on definite clinical grounds or suspicion of infection. All patients have blood sampled for culture on admission to the PICU and endotracheal aspirates (ETAs) are routinely sent for culture for ventilated patients twice weekly. Patients who were transferred from another hospital or had an admission to a healthcare facility within two weeks of presentation with admission cultures positive were labelled as HAl but excluded from the study because these would not have been in the PICU.

\section{The intervention}

At implementation of the BCA bundles, the Hospital Acquired Infections in the ICU team met with the heads of the PICU and chose a BCA champion to enforce the protocols. Each PICU chart was to be stamped with the BCA bundles compliance stamp, which allowed for review of compliance with the bundle elements and line/catheter necessities twice daily. An audit procedure was then followed on a two-monthly basis to review bundle compliance. There was specific training for the nurses in the PICU by the Infection Prevention and Control Committee on bundle elements. This training did not include all doctors and auxiliary staff.

HAl occurrence was recorded per month then tallied for the time periods before and after the implementation of the Infection Control Programme, which occurred in the month of August 2016. HAl rates were calculated per 100 admissions, per 1000 patient days and per 1000 device days and categorised into BSIs, urinary tract infections (UTIs), VAP and other.

\section{Data analysis}

Relative risk (RR) with confidence intervals $(\mathrm{Cl})$ was used to measure the effect of the Infection Control Programme on HAI occurrence with $p$-values to assess the significance of observed differences before and after. Proportions and categorical variables were compared using Pearson's chi-square test or Fisher's exact test as appropriate. All analyses were performed using SPSS (version 24; IBM Corp, Armonk, NY, USA) with the level of significance set at $p<0.05$.

\section{Results}

There was a total of 449 admissions to the PICU in the year prior to the Infection Control Programme and 410 in the year after (Table 1). Patient days before were 2537 and after 2532 . Device days were 4118 before and 3321 after. There were three months in the post-intervention period that had incomplete device data for urinary catheters and central venous catheters (CVCs). These three months could therefore not be included in the after analysis for device day infection rates.

Some $44 \%$ of admissions both before and after were in the less than one-year age group. There were similar proportions of medical and surgical admissions before and after the intervention. There were 102 HAls before and 81 after the intervention. The most common category of HAI before and after was VAP, followed by BSI and then UTI.

\section{Organisms}

There were more Gram-negative organisms ( $n=164,81 \%)$ identified than Gram-positive ( $n=38,19 \%)$. Among the Gram-negative organisms, the most prevalent organism was Klebsiella 
Table 1: PICU patient and line characteristics

\begin{tabular}{|c|c|c|c|}
\hline Admissions & & $\begin{array}{c}\text { Before }(n=449) \\
\text { no. }(\%)\end{array}$ & $\begin{array}{c}\text { After }(n=410) \\
\text { no. }(\%)\end{array}$ \\
\hline \multirow[t]{2}{*}{ Clinical category } & Medical & $242(54)$ & $216(53)$ \\
\hline & Surgical & $207(46)$ & $194(47)$ \\
\hline \multirow[t]{4}{*}{ Age groups } & $<28$ days & $18(4)$ & $12(3)$ \\
\hline & 28 days to $<1$ year & $193(43)$ & $152(37)$ \\
\hline & 1 year to 5 years & $127(28)$ & $129(32)$ \\
\hline & $>5$ years & $111(25)$ & $117(28)$ \\
\hline Patient days & & 2537 & 2532 \\
\hline Device days & & Before $(n=4118)$ & After $(n=3321)^{*}$ \\
\hline \multirow[t]{3}{*}{ Type of device } & Central venous catheter & $721(18)$ & $519(16)^{*}$ \\
\hline & Urinary catheter & $1903(46)$ & $1309(39)^{*}$ \\
\hline & Endotracheal tube (ETT) & $1494(36)$ & $1493(45)$ \\
\hline
\end{tabular}

*In the post-intervention period three months had incomplete device data and were therefore not included in the analysis.

pneumoniae ( $n=50,25 \%)$, almost half of which were multidrug resistant. Other Gram-negative organisms identified included Acinetobacter baumannii ( $n=32,16 \%)$ and Pseudomonas aeruginosa ( $n=28,14 \%$ ) (Table 2: HAl organism profile).

\section{HAl occurrence}

There was an absolute decrease in HAls from 102 to 81 . The rate of HAl decreased from 23 per 100 admissions prior to the intervention to 20 per 100 admissions after the intervention (RR 0.9, $95 \% \mathrm{Cl} 0.51-1.48, p=0.61$ ) and from 40 per 1000 patient days to 32 per 1000 patient days (RR $0.8,95 \% \mathrm{Cl} 0.51-1.56, p=0.34$ ). There was a statistically significant decrease in BSI per 1000 CVC days from 36 per 1000 before intervention to 15 per 1 000 after (RR 0.4, 95\% Cl 0.23-0.79, $p=0.004$ ). Reductions in HAI were also seen in BSIs and UTIs but these were not statistically significant. VAP showed a slight increase per $100 \mathrm{admis}-$ sions (RR 1.4, 95\% Cl 0.48-3.70; $p=0.58$ ), per 1000 patient days and per $1000 \mathrm{ETT}$ days (see Table 3 ).

\section{Discussion}

Our study looked at $\mathrm{HAl}$ occurrence in 449 admissions before and 410 admissions after the implementation of a

Table 2: HAl organism profile

\begin{tabular}{|c|c|c|c|}
\hline Type & Organism & $\begin{array}{c}\text { Before } \\
\left(n=109^{\S}\right) \\
\text { no. }(\%)\end{array}$ & $\begin{array}{c}\text { After } \\
\left(n=93^{\S}\right) \\
\text { no. }(\%)\end{array}$ \\
\hline \multirow{8}{*}{$\begin{array}{l}\text { Gram- } \\
\text { negative }\end{array}$} & All Klebsiella pneumoniae & 27 (24) & $23(25)$ \\
\hline & Multidrug-resistant Klebsiella & $13(48)$ & $11(48)$ \\
\hline & Acinetobacter baumannii & $20(18)$ & $12(13)$ \\
\hline & Pseudomonas aeruginosa & $9(8)$ & $19(20)$ \\
\hline & Escherichia coli & $11(10)$ & $10(11)$ \\
\hline & Serratia marcescens & $5(5)$ & $0(0)$ \\
\hline & Other* & $16(15)$ & $12(13)$ \\
\hline & Total & $88(80)$ & $76(82)$ \\
\hline \multirow{4}{*}{$\begin{array}{l}\text { Gram- } \\
\text { positive }\end{array}$} & Enterococcus species & $14(13)$ & $14(15)$ \\
\hline & Staphylococcus aureus & $6(6)$ & $3(3)$ \\
\hline & Streptococcus mitis & $1(1)$ & $0(0)$ \\
\hline & Total & $21(20)$ & 17 (18) \\
\hline
\end{tabular}

${ }^{5}$ Organisims identified are more than the total HAI because some cultures yielded more than one organism.

*Other included Stenotrophomonas maltophilia and Citrobacter, Enterobacter, Morganella and Proteus species. comprehensive Infection Control Programme. Our results showed a trend towards patients being less likely to acquire an HAl after the intervention. The most noteworthy finding was the significant decrease in BSI per 1000 CVC days with

Table 3: HAl occurrence before and after implementation of the Infection Control Programme, and relative risk for $\mathrm{HAl}$ after the intervention

\begin{tabular}{|c|c|c|c|c|}
\hline Factor & $\begin{array}{c}\text { Before } \\
(n= \\
102)\end{array}$ & $\begin{array}{l}\text { After } \\
(n= \\
\mathbf{8 1})\end{array}$ & $\begin{array}{c}\text { Relative risk } \\
(95 \% \\
\text { confidence } \\
\text { interval) }\end{array}$ & $\begin{array}{c}p- \\
\text { value }\end{array}$ \\
\hline $\begin{array}{l}\text { HAl per } 100 \\
\text { admissions }\end{array}$ & 23 & 20 & $0.9(0.5-1.5)$ & 0.61 \\
\hline $\begin{array}{l}\text { HAl per } 1000 \\
\text { patient days }\end{array}$ & 40 & 32 & $0.8(0.5-1.3)$ & 0.34 \\
\hline BSI number & 26 & 15 & $0.7(0.4-1.3)$ & 0.27 \\
\hline $\begin{array}{l}\text { Per } 100 \\
\text { admissions }\end{array}$ & 6 & 4 & $0.7(0.2-2.3)$ & 0.52 \\
\hline $\begin{array}{l}\text { Per } 1000 \\
\text { patient days }\end{array}$ & 10 & 6 & $0.6(0.2-1.6)$ & 0.32 \\
\hline $\begin{array}{l}\text { Per } 1000 \text { CVC } \\
\text { days }\end{array}$ & 36 & $15^{*}$ & $0.4(0.2-0.8)$ & 0.004 \\
\hline UTI number & 16 & 10 & $0.8(0.4-1.6)$ & 0.52 \\
\hline $\begin{array}{l}\text { Per } 100 \\
\text { admissions }\end{array}$ & 4 & 2 & $0.5(0.1-2.7)$ & 0.42 \\
\hline $\begin{array}{l}\text { Per } 1000 \\
\text { patient days }\end{array}$ & 6 & 4 & $0.7(0.2-2.4)$ & 0.53 \\
\hline $\begin{array}{l}\text { Per } 1000 \\
\text { urinary } \\
\text { catheter days }\end{array}$ & 8 & $5^{*}$ & $0.6(0.2-1.9)$ & 0.41 \\
\hline VAP number & 28 & 31 & $1.4(0.9-2.1)$ & 0.12 \\
\hline $\begin{array}{l}\text { Per } 100 \\
\text { admissions }\end{array}$ & 6 & 8 & $1.3(0.5-3.7)$ & 0.58 \\
\hline $\begin{array}{l}\text { Per } 1000 \\
\text { patient days }\end{array}$ & 11 & 12 & $1.1(0.5-2.5)$ & 0.83 \\
\hline $\begin{array}{l}\text { Per } 1000 \text { ETT } \\
\text { days }\end{array}$ & 19 & 21 & $1.1(0.6-2.0)$ & 0.75 \\
\hline $\begin{array}{l}\text { 'Other' } \\
\text { number }\end{array}$ & 32 & 25 & $1.0(0.6-1.5)$ & 0.94 \\
\hline $\begin{array}{l}\text { Per } 100 \\
\text { admissions }\end{array}$ & 7 & 6 & $0.9(0.3-2.5)$ & 0.77 \\
\hline $\begin{array}{l}\text { Per } 1000 \\
\text { patient days }\end{array}$ & 13 & 10 & $0.8(0.3-1.8)$ & 0.53 \\
\hline
\end{tabular}

*In the post-intervention period three months had incomplete line data and were therefore not included in the after analysis. 
patients being 0.42 times as likely to acquire a BSI after the intervention ( $\mathrm{RR} 0.42,95 \% \mathrm{Cl} 0.23-0.79, p=0.004$ ).

In the after period there were 21 fewer HAls. For every 100 admissions there were 3 fewer HAls and for every 1000 patient days there were 8 fewer HAls. When calculated per admissions, per patient days and per device days there was no difference in relative risk ( $\mathrm{Cls}$ include $1, p>0.05)$. Analysis of other subgroups showed absolute decreases in occurrence of BSIs and UTIs but the findings were not statistically significant.

VAP occurrence increased slightly. This could be explained by the frequency of routine ETAs being taken biweekly giving increased positive cultures, some of which may have reflected colonisation rather than infection.

Gram-negative organisms predominated (81\%), which was similar to studies from Tygerberg Hospital in Cape Town in both paediatric and neonatal settings. The incidence was higher, however, than the $66 \%$ of BSI reported by Tygerberg Children's Hospital over a six-year period from 2008 to 2013 . $^{15}$ Of the Gram-negative organisms, Klebsiella was the most prevalent species and this too was similar to data from Tygerberg Children's Hospital and to those from a newly opened PICU in Turkey over a four-year period (2011-2014). ${ }^{16,17}$

In our unit, the implementation of the Infection Control Programme showed the expected reduction in BSIs but not in UTIs and VAP. In other settings where BCA bundles have been implemented a greater than $50 \%$ reduction in infections has been reported, ${ }^{18-20}$ suggesting that there is room for improvement in our unit.

One of the main challenges of infection prevention strategies is health-worker compliance with bundle protocols. All aspects of the bundle must be adhered to in order to see optimal reduction in CLABSI and VAP. ${ }^{19}$ In a study conducted at Tygerberg Hospital looking at paediatric healthcare providers' knowledge, attitudes and practice with regard to infection control, knowledge scores were low but self-reported compliance with infection control measures was high. It was concluded that in-service and undergraduate training in hand hygiene and routes of infection transmission should be emphasised. ${ }^{21}$ In our unit, there is a high turnover of staff resulting in inconsistent teaching of the principles and practices of the Infection Control Programme. In addition, monitoring of bundle compliance may have been suboptimal for reasons of workload pressure and staffing constraints.

\section{Limitations}

The before-after quasi-experimental design, while making the study feasible, contains a risk of bias and confounding. Although there were 39 fewer admissions in the year following the intervention, the number of patient days differed by 5 , indicating that the length of stay was longer in the after period, which is a recognised risk for acquiring an $\mathrm{HAl}$ and could have masked the effect of the Infection Control Programme. The proportion of surgical admissions (less at risk for infection, and shorter stay) both before and after intervention was similar; however, in the before period there were more admissions of infants (< 1 year) who are more vulnerable to acquiring infections.

The incomplete line data for CVCs and urinary catheters for three of the months in the after period meant that data for these three months could not be analysed and were therefore omitted. This decreased the sample size for BSIs and UTIs and device days, but is unlikely to have affected proportions and rates. Organism profiles were similar in both periods.

Although the baseline characteristics of the before and after groups were similar, the changes in staff and the availability of equipment and resources at different times were not measurable and may have had an impact on risk of acquiring HAI.

\section{Recommendations}

The significant decrease in BSIs per 1000 CVC days and an overall decreasing trend in $\mathrm{HAl}$ were encouraging. The less than expected reduction in HAls provides opportunity in the Grey's PICU for further research into the most effective processes for implementation of an Infection Control Programme as well as opportunity for ongoing action to further reduce HAI rates.

Achieving high-quality programme implementation is critical to achieving expected outcomes. ${ }^{22}$ Durlak et al. describe four main phases in a quality implementation framework: (1) Initial considerations regarding the host setting, (2) Creating a structure for implementation, (3) Ongoing structure once implementation begins and (4) Improving future applications. ${ }^{23}$ Broken down into steps, the implementation process involves awareness, adopting the concept, mobilisation of resources, evidence of practice, evidence of routine, and integration and sustainable practice. ${ }^{24}$ These steps could provide a framework for reviewing the Infection Control Programme implementation and may provide concrete proposals for better impact.

In the meantime, intensification of orientation of new staff, enforcement of bundle protocols and monitoring of adherence to all bundle elements is advised. Involving clinicians in the HAI review process may improve both HAI identification and awareness as well as bundles enforcement and stewardship.

\section{Conclusion}

HAls remain very important globally and also in Grey's Hospital. Our downward trend in HAls after the intervention was less than expected. Further research or audit is needed in our PICU to ascertain reasons for this with a view to optimising the impact of the Infection Control Programme and BCA.

\section{Ethics review}

The research protocol was reviewed and approved by the Biomedical Research Ethics Committee (University of KwaZuluNatal, South Africa) (BE003/17).

Acknowledgements - The authors would like to thank Sr Green and Sr Peet from the Greys HAI Quality Improvement Project team for their hard work trying to reduce HAl at Grey's Hospital and for allowing access to their HAl database. Many thanks to the PICU team for allowing access to their registers and patient records.

Disclosure statement - No potential conflict of interest was reported by the authors.

\section{ORCID}

Mark E Patrick (D) http://orcid.org/0000-0001-9912-1870

Wilbert Sibanda (D) http://orcid.org/0000-0001-5702-2436

Kevin B Spicer (D) http://orcid.org/0000-0001-7154-8020 


\section{References}

1. Mermel LA. Prevention of intravascular catheter-related infections. Ann Intern Med. 2000 March 7;132(5):391-402. http://annals.org/ aim/article-abstract/713299/prevention-intravascular-catheter-relate d-infections.

2. Soufir L, Timsit JF, Mahe C, et al. Attributable morbidity and mortality of catheter-related septicemia in critically ill patients: a matched, riskadjusted, cohort study. Infect Control Hosp Epidemiol. 1999 June;20 (6):396-401

3. Aiken AM, Allegranzi B, Scott JA, et al. Antibiotic resistance needs global solutions. Lancet Infect Dis. 2014 July; 14(7):550-1. https://www.thelance t.com/journals/laninf/article/PIIS1473-3099(14)70709-1/abstract.

4. Rosenthal VD. Health-care-associated infections in developing countries. Lancet. 2011 January 15;377(9761):186-8. https://www. thelancet.com/journals/lancet/article/PIIS0140-6736(10)62005-3/fulltext?_eventld=login\&code=lancet-site.

5. Klevens RM, Edwards JR, Richards Jr CL, et al. Estimating health careassociated infections and deaths in U.S. hospitals, 2002. Public Health Rep. 2007 March-April;122(2):160-6. http://journals.sagepub.com/ doi/abs/10.1177/003335490712200205.

6. Lowman W. Active surveillance of hospital-acquired infections in South Africa: implementation, impact and challenges. S Afr Med J. 2016 April 07;106(5):489. http://www.samj.org.za/index.php/samj/ article/view/10783.

7. Allegranzi B, Nejad SB, Combescure C, et al. Burden of endemic health-care-associated infection in developing countries: systematic review and meta-analysis. Lancet. 2011;377(9761):228-41. https:// www.thelancet.com/journals/lancet/article/PIIS0140-6736(10)614584/abstract.

8. Rosenthal VD, Al-Abdely HM, El-Kholy AA, et al. International nosocomial Infection Control Consortium report, data summary of 50 countries for 2010-2015: device-associated module. Am J Infect Control. 2016 December 01;44(12):1495-504. https://www. sciencedirect.com/science/article/pii/S0196655316308057.

9. Geldenhuys C, Dramowski A, Jenkins A, et al. Central-line-associated bloodstream infections in a resource-limited South African neonatal intensive care unit. S Afr Med J. 2017 August 25;107(9):758-62. http:// www.samj.org.za/index.php/samj/article/view/12041.

10. Walsh Y, van den Bergh D, Kantor G, et al. Best Care Always! A collaborative quality initiative for consistent best practice and patient safety. 2009 Available at: http://www.bestcare.org.za.

11. Resar R, Pronovost $P$, Haraden $C$, et al. Using a bundle approach to improve ventilator care processes and reduce ventilator-associated pneumonia. Jt Comm J Qual Patient Saf. 2005;31(5):243-8. https:// www.jointcommissionjournal.com/article/S1553-7250(05)31031-2/ abstract.

12. Spicer KB, Green J, Dhada B. Hospital-acquired infections in paediatric medical wards at a tertiary hospital in KwaZulu-Natal, South Africa. Paedtr Int Child Health. 2018 Feb;38(1): 53-59.

13. Richards MJ, Edwards JR, Culver DH, et al. Nosocomial infections in pediatric intensive care units in the United States. Pediatrics. 1999;103(4):e39.
14. Hendricks $\mathrm{CL}$, McKerrow NH, Hendricks RJ. Factors present on admission associated with increased mortality in children admitted to a paediatric intensive care unit (PICU). SAJCH. 2016 March;10(1):5762. http://www.sajch.org.za/index.php/SAJCH/article/view/1048.

15. Morkel G, Bekker A, Marais BJ, et al. Bloodstream infections and antimicrobial resistance patterns in a South African neonatal intensive care unit. Paediatr Int Child Health. 2014 May;34(2):108-14. https:// www.researchgate.net/publication/260756836_Bloodstream_ infections_and_antimicrobial_resistance_patterns_in_a_South_ African_neonatal_intensive_care_unit.

16. Dramowski A, Cotton MF, Rabie $\mathrm{H}$, et al. Trends in paediatric bloodstream infections at a South African referral hospital. BMC Pediatr. 2015 April 02;15:33. https://bmcpediatr.biomedcentral.com/articles/ 10.1186/s12887-015-0354-3.

17. Atici S, Soysal A, Kepenekli Kadayifci E, et al. Healthcare-associated infections in a newly opened pediatric intensive care unit in Turkey: results of four-year surveillance. J Infect Dev Ctries. 2016 March 31;10(3):254-9. https://jidc.org/index.php/journal/article/ download/27031457/1473.

18. Kantor G, van den Bergh D, Brink A. Best care ... ALWAYS. South Afr J Epidemiol Infect. 2011;26(1):3-5.

19. Smulders CA, van Gestel JP, Bos AP. Are central line bundles and ventilator bundles effective in critically ill neonates and children? Intensive Care Med. 2013 August;39(8):1352-8. http://icmjournal. esicm.org/Journals/abstract.html?doi=10.1007/s00134-013-2927-7.

20. Ista $E$, van der Hoven $B$, Kornelisse RF, et al. Effectiveness of insertion and maintenance bundles to prevent central-line-associated bloodstream infections in critically ill patients of all ages: a systematic review and meta-analysis. Lancet Infect Dis. 2016 June;16(6):724-34. https://www.thelancet.com/journals/laninf/article/PIIS1473-3099 (15)00409-0/abstract?code=lancet-site.

21. Dramowski A, Whitelaw A, Cotton MF. Healthcare-associated infections in children: knowledge, attitudes and practice of paediatric healthcare providers at Tygerberg Hospital, Cape Town. Paediatr and Int Child Health. 2016 August;36(3):225-31. https://www. researchgate.net/publication/276071547_Healthcare-associated infections_in_children_knowledge_attitudes_and_practice_of_ paediatric_healthcare_providers_at_Tygerberg_Hospital_Cape_ Town.

22. Durlak J. The importance of quality implementation for research, practice, and policy. ASPE Research Brief. 2013. (US Department of Health and Human Services). Available from: http://www.aspe.hhs. gov.

23. Meyers DC, Durlak JA, Wandersman A. The quality implementation framework: A synthesis of critical steps in the implementation process. Am J Community Psychol. 2012;50(3-4):462-80.

24. Bergh AM, Arsalo I, Malan AF, et al. Measuring implementation progress in kangaroo mother care. Acta Paediatr. 2005 August;94 (8):1102-8. https://onlinelibrary.wiley.com/doi/full/10.1111/j.16512227.2005.tb02052.x. 